\title{
DEVELOPMENT AND VALIDATION OF STABILITY INDICATING RP-HPLC METHOD FOR DETERMINATION OF $\beta$-ACETYLDIGOXIN
}

\author{
MEGHA SHARMA, NEERAJ MAHINDROO* \\ Shoolini University, Post Box: 9, Head Post Office, The Mall, Solan, Himachal Pradesh, 173212, India \\ Email: neeraj.mahindroo@shooliniuniversity.com
}

Received: 08 Nov 2016, Revised and Accepted: 26 Dec 2016

\section{ABSTRACT}

Objective: The objective of the present study was to develop and validate a novel stability indicating reverse phase-high performance liquid chromatography (RP-HPLC) method for determination of $\beta$-acetyldigoxin, an active pharmaceutical ingredient (API).

Methods: The chromatographic separation was carried out on Agilent Technologies 1200 series HPLC system equipped with photo diode array detector and C-18 (4.6x250 mm, $5 \mu$ ) column. The mobile phase consisted of water: acetonitrile $(65: 35 \mathrm{v} / \mathrm{v})$, delivered at a flow rate of $1.5 \mathrm{ml} / \mathrm{min}$ and eluents were monitored at $225 \mathrm{~nm}$.

Results: The retention time of $\beta$-acetyldigoxin was $9.2 \mathrm{~min}$. The method was found to be linear $\left(\mathrm{R}^{2}=0.9995\right)$ in the range of $31.25-500 \mu \mathrm{g} / \mathrm{ml}$. The accuracy studies showed the mean percent recovery of $101.02 \%$. LOD and LOQ were observed to be $0.289 \mu \mathrm{g} / \mathrm{ml}$ and $0.965 \mu \mathrm{g} / \mathrm{ml}$, respectively. The method was found to be robust and system suitability testing was also performed. Forced degradation analysis was carried out under acidic, alkaline, oxidative and photolytic stress conditions. Significant degradation was observed under tested conditions, except for oxidative condition. The method was able to separate all the degradation products within runtime of 20 min and was able to determine $\beta$-acetyldigoxin unequivocally in presence of degradation products.

Conclusion: The novel, economic, rapid and simple method for analysis of $\beta$-acetyldigoxin is reported. The developed method is suitable for routine quality control and its determination as API, and in pharmaceutical formulations and stability study samples.

Keywords: $\beta$-Acetyldigoxin, HPLC, Stability indicating assay method

(C) 2016 The Authors. Published by Innovare Academic Sciences Pvt Ltd. This is an open access article under the CC BY license (http://creativecommons.org/licenses/by/4.0/) DOI: http://dx.doi.org/10.22159/ijap.2017v9i1.16076

\section{INTRODUCTION}

\section{$\beta$-Acetyldigoxin}

$\beta$-Acetyldigoxin, 3 $\beta$-[(4-O-acetyl-2,6-Dideoxy- $\beta$-D-ribo-hexopyranosyl$(1 \rightarrow 4)$-0-2,6-dideoxy- $\beta$-D-ribo-hexopyranosyl-( $1 \rightarrow 4)$-2,6-dideoxy- $\beta$ D-ribo-hexopyranosyl)oxy]-12 $\beta, 14$-dihydroxy-5 $\beta$-card-20(22)enolide (fig. 1) [1], is a prodrug of digoxin, a well-established agent for managing heart failure and controlling rapid ventricular rate in atrial fibrillation $[2,3]$.

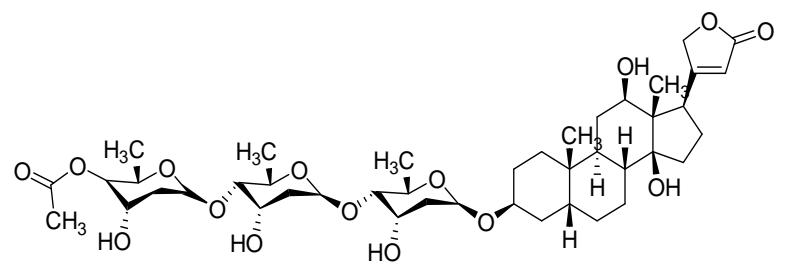

Fig. 1: Chemical structure- $\beta$-Acetyldigoxin [1]

Digoxin affects cardiac rate, rhythm and the force of cardiac contraction. It increases vagal activity and slows down conduction in the atrioventricular (AV) node. Digoxin binds to the $\mathrm{K}^{+}$-binding site of $\mathrm{Na}^{+} / \mathrm{K}^{+}$-ATPase pump and increases the force of contraction [4]. The acetyl group of $\beta$-acetyldigoxin is cleaved on passage through intestinal wall and active digoxin reaches the heart [5]. $\beta$ Acetyldigoxin is a substrate of p-glycoprotein and has a similar transport mechanism as digoxin [6]. $\beta$-Acetyldigoxin is reported to have better absorption [7], efficacy and tolerance [8], as compared to parent drug, digoxin. Like digoxin, $\beta$-acetyldigoxin also belongs to the category of narrow therapeutic index drugs $[9,10]$. Digoxin and $\beta$-acetyldigoxin are two of the most important marketed cardiac glycosides $[11,12]$.

\section{$\beta$-Acetyldigoxin-Need for novel stability indicating assay method}

Stability indicating assay method is a validated analytical procedure that is able to measure unequivocally the drug substance in presence of degradation products $[13,14]$. Previously reported HPLC methods for analytical determination of $\beta$-acetyldigoxin simultaneously with related cardiac glycosides, indicate its retention time at $17.3 \mathrm{~min}$ [15] and $23.4 \mathrm{~min}$ [16], respectively. Since elution is quite late, these methods aren't suitable for routine quality control. Also, the European Pharmacopoeia HPLC assay method [1] for $\beta$ acetyldigoxin utilizes gradient elution. There are various disadvantages associated with gradient elution such as poor robustness, longer equilibration periods and complexity of method development. The column life is also shortened and method transfer is difficult [17]. No stability indicating assay method for forced degradation studies, as per regulatory guidelines, has been reported for the determination of $\beta$-acetyldigoxin.

The present report describes development and validation of a novel and rapid isocratic stability indicating assay method for determination of $\beta$-acetyldigoxin.

\section{MATERIALS AND METHODS}

\section{Chemicals and reagents}

Analytical grade $\beta$-acetyldigoxin was purchased from Clearsynth Labs, Mumbai. HPLC grade solvents (water, methanol, acetonitrile) were procured from Loba Chemie and Fischer Scientific. All chemicals were analytical grade and were used as supplied.

\section{Instrumentation}

The RP-HPLC method was developed on Agilent Technologies 1200 series HPLC system. It was equipped with Agela Technologies C-18 $(4.6 \times 250 \mathrm{~mm}, 5 \mu, 100 \AA)$ column, binary pump, photo diode array detector, auto sampler and EzChrome Elite software. Digital temperature controlled oven (Relitech) and UV chamber (Inco) were used for forced degradation studies. 


\section{Preparation of stock solution}

Accurately weighed $\beta$-acetyldigoxin was transferred to volumetric flask and volume was made up with methanol: acetonitrile (50:50 $\mathrm{v} / \mathrm{v}$ ) to obtain a $1000 \mu \mathrm{g} / \mathrm{ml}$ stock solution.

\section{Optimization of chromatographic conditions}

The detection wavelength for $\beta$-acetyldigoxin was selected according to European Pharmacopoeia method [1]. The chromatographic conditions were optimized to get a sharp and symmetric peak. Initial experiments, beginning with water: acetonitrile, $50: 50 \mathrm{v} / \mathrm{v}$ at flow rate of $1.0 \mathrm{ml} / \mathrm{min}$, resulted in delayed elution and a broad peak.

Mobile phase, flow rate and injection volume were optimized to get an optimum elution time and a symmetrical sharp peak. The run time should be 2.5 times the retention time of peak of analyte for optimum analysis of degradation products [13], so the run time of 20 min was selected for the study. The mode of elution was isocratic and separation was carried out at ambient temperature.

\section{Calibration curve}

The stock solution of $\beta$-acetyldigoxin $(1000 \mu \mathrm{g} / \mathrm{ml})$ was serially diluted with methanol: acetonitrile $(50: 50 \mathrm{v} / \mathrm{v})$ to prepare solutions with concentration of $31.25,62.5,125,250,500 \mu \mathrm{g} / \mathrm{ml}$, respectively. Each solution was injected in triplicates to obtain the chromatograms. A calibration curve was constructed by plotting average peak area versus concentration.

\section{Method validation and system suitability testing}

The method for analytical determination of $\beta$-acetyldigoxin was validated and tested for system suitability according to International Conference on Harmonization (ICH), United States Food and Drug Administration (FDA) and United States Pharmacopoeia (USP) guidelines [18-20].

\section{Linearity}

Linearity was determined by computing correlation coefficient from calibration curve, in the range of $31.25-500 \mu \mathrm{g} / \mathrm{ml}$.

\section{Precision}

For interday precision studies, analysis was carried out for three consecutive days at three different concentrations, $125,250,500$ $\mu \mathrm{g} / \mathrm{ml}$ respectively, in triplicate. To study intraday precision, analysis was carried out at three different times in a day at three different concentrations, $125,250,500 \mu \mathrm{g} / \mathrm{ml}$ respectively, in triplicate. \% RSD (relative standard deviation) of peak areas were calculated for both the studies.

\section{Accuracy}

Standard addition method was employed for accuracy studies. Spiking was done at levels of 80,100 and $120 \%$ in previously analyzed sample of $250 \mu \mathrm{g} / \mathrm{ml}$ to measure percent recovery by the assay of known added amounts of analyte.

\section{Robustness}

Robustness was measured by making small but deliberate changes in detection wavelength $( \pm 5 \mathrm{~nm})$, flow rate $( \pm 0.1 \mathrm{ml} / \mathrm{min}$.) and organic content in mobile phase ( \pm 2 units). \% RSD of peak areas was calculated for each of the evaluations.

\section{Limit of detection (LOD) and limit of quantification (LOQ)}

The specificity of the method was determined by forced degradation studies. LOD and LOQ were determined using the formulas, LOD = $3.3 \times \sigma / \mathrm{S}$ and $\mathrm{LOQ}=10 \times \sigma / \mathrm{S}$, where, ' $\sigma$ ' is the standard deviation of the response and ' $S$ ' is the slope of calibration curve.

\section{System suitabilitytesting}

System suitability was evaluated by analyzing six replicates (500 $\mu \mathrm{g} / \mathrm{ml}$ ) of $\beta$-acetyldigoxin. Suitability for intended use was tested in terms of \% RSD of retention time, \% RSD of peak area, tailing factor $\left(T_{f}\right)$, asymmetry factor $\left(A_{s}\right)$, number of theoretical plates $(N)$ and height equivalent to theoretical plates (HETP).

\section{Specificity-forced degradation studies}

$\beta$-acetyldigoxin $(1 \mathrm{mg} / \mathrm{ml})$ was subjected to acidic stress $(0.1 \mathrm{~N}$ $\mathrm{HCl}, 40{ }^{\circ} \mathrm{C}, 30 \mathrm{~min}$.), alkaline stress $\left(0.1 \mathrm{~N} \mathrm{NaOH}, 40{ }^{\circ} \mathrm{C}, 30 \mathrm{~min}\right.$. $)$, oxidative stress $\left(30 \% \mathrm{H}_{2} \mathrm{O}_{2}, \mathrm{RT}, 24 \mathrm{~h}\right)$ and photo stress (UV, 365 $\mathrm{nm}, 96 \mathrm{~h})$. The stressed samples were appropriately diluted before injection. For each stress condition, three chromatograms were recorded, namely; control (analyte not subjected to stress), blank (stressor and solvent) and stressed (analyte subjected to stress).

\section{RESULTS AND DISCUSSION}

\section{Chromatographic conditions and calibration curve}

The chromatographic conditions were optimized, after multiple trials, to get a symmetric optimum eluting peak. The average retention time for $\beta$-acetyldigoxin was $9.207 \pm 0.031 \mathrm{~min}$. (n=3) (fig. 2). Thus, the developed method provides faster elution time than the previously reported methods $[15,16]$.

The method is isocratic and is thus simple as compared to European Pharmacopoeia method [1], and also overcomes the limitations of a gradient method [17]. The method is rapid and is thus cost effective. The method does not use buffer and therefore, various additional steps like $\mathrm{pH}$ adjustment [21] are eliminated. Also, buffers are aggressive towards column packing and longer periods of column washing are needed [22].

Optimized chromatographic conditions are summed up in table 1. An injection of blank (only solvent, no analyte) was also run (fig. 3). A calibration curve was (fig. 4) plotted to compute regression equation and correlation coefficient.

Table 1: Optimized chromatographic conditions

\begin{tabular}{lll}
\hline S. No. & Parameter & Condition \\
\hline 1 & Stationary phase & Innoval C-18 column $(4.6 \times 250 \mathrm{~mm}, 5 \mu)$ \\
2 & Mobile phase & Water: acetonitrile $(65: 35 \mathrm{v} / \mathrm{v})$ \\
3 & Flow rate & $1.5 \mathrm{ml} / \mathrm{min}$ \\
4 & Detector & Photo diode array \\
5 & Injection volume & $5 \mu \mathrm{l}$ \\
6 & Detection wavelength & $225 \mathrm{~nm}$ \\
7 & Retention Time & $9.207 \mathrm{~min}$ \\
8 & Diluent/solvent & Methanol: acetonitrile $(50: 50 \mathrm{v} / \mathrm{v})$ \\
9 & Run time & 20 min \\
\hline
\end{tabular}




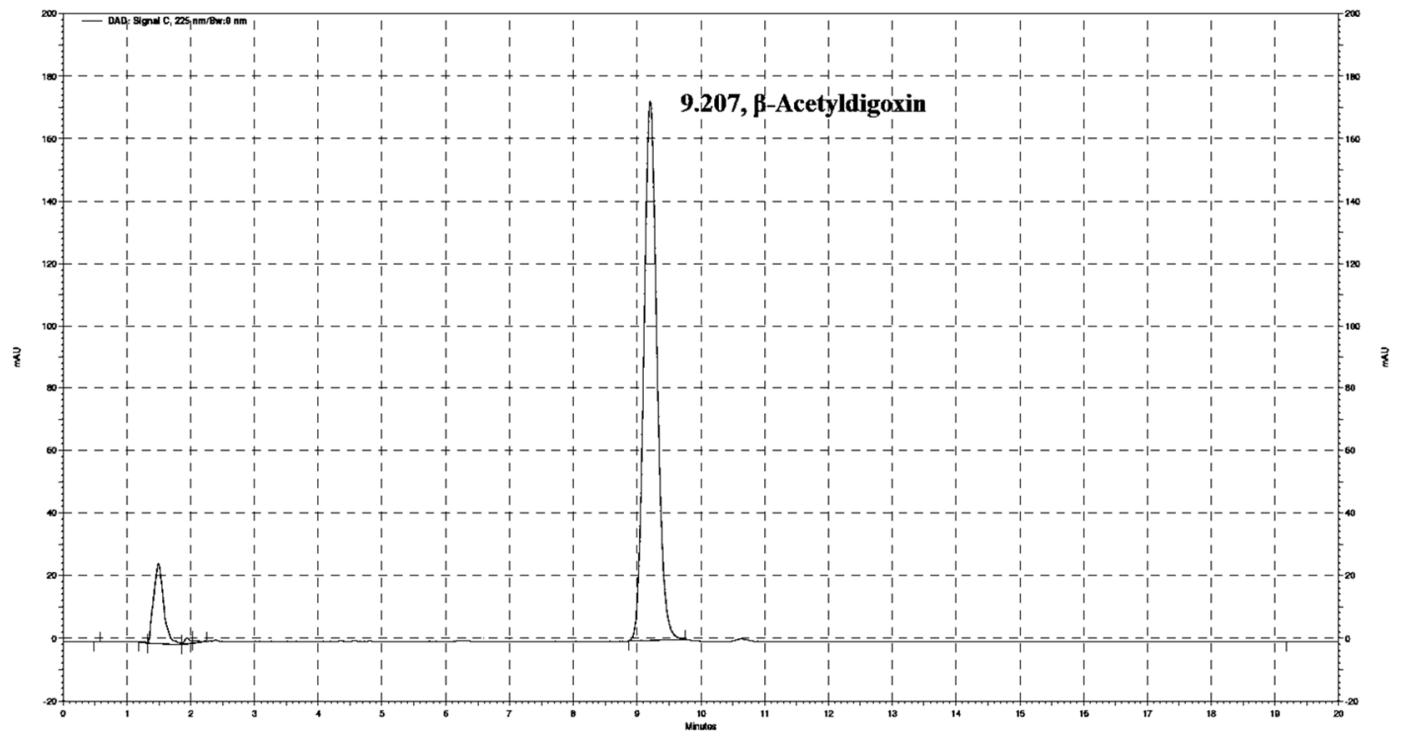

Fig. 2: Chromatogram for $\beta$-acetyldigoxin showing elution time of $9.207 \mathrm{~min}$

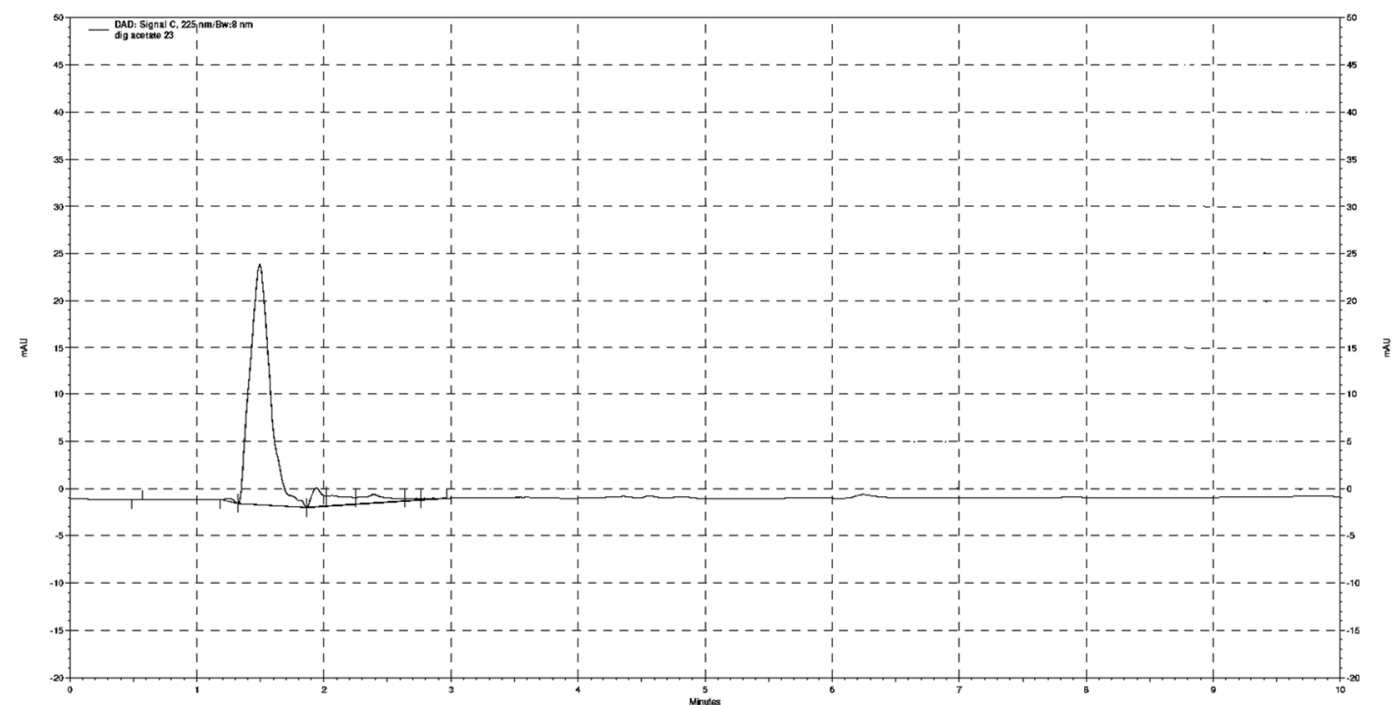

Fig. 3: Blank (Methanol: Acetonitrile $(50: 50 \mathrm{v} / \mathrm{v})$ ) does not show any peak around elution time of $\beta$-acetyldigoxin

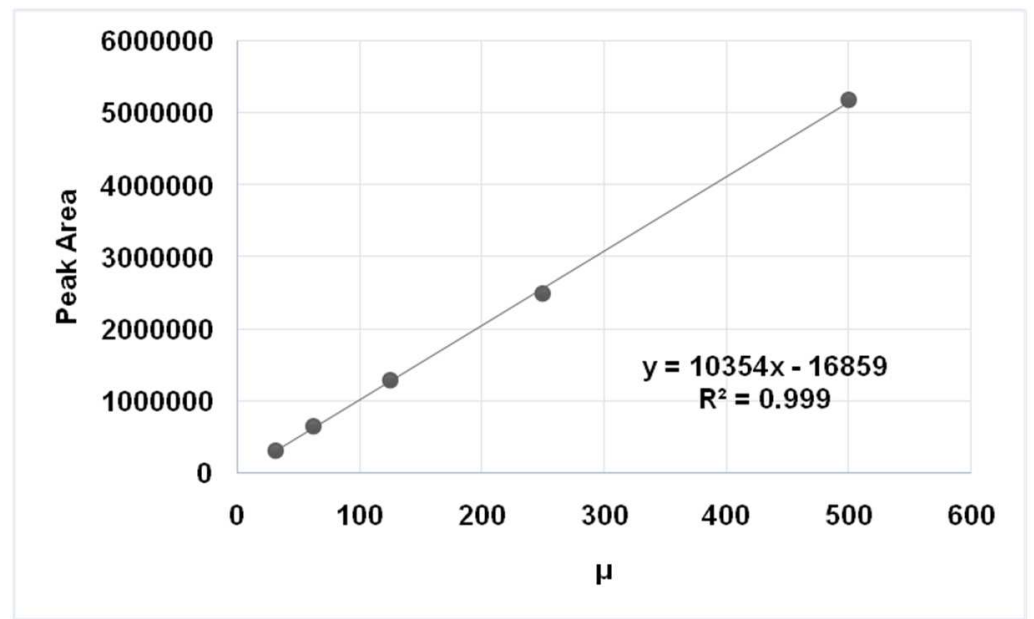

Fig. 4: Calibration curve for $\beta$-acetyldigoxin for concentration range from 31.25 to $500 \mu \mathrm{g} / \mathrm{ml}$ 


\section{Method validation and system suitability testing}

The developed method was validated according to regulatory guidelines [18-20]. Results of validation and system suitability testing are summed up in table 2 . The results complied with the acceptance criteria laid down under regulatory guidelines $[20,23]$ with \% RSD values, tailing factor, asymmetry factor and height equivalent to theoretical plates being well below the acceptable limits and correlation coefficient, and number of theoretical plates were above the minimum acceptance criterion.

Table 2: Method validation and system suitability parameters

\begin{tabular}{lll}
\hline Parameter & Observation & Acceptance criterion [20, 23] \\
\hline Regression equation & $\mathrm{y}=10354 \mathrm{x}-16859$ & - \\
Correlation coefficient & 0.9995 & $\geq 0.995$ \\
Range & $31.25-500 \mu \mathrm{g} / \mathrm{ml}$ & - \\
Average \%RSD (Peak area, n=5) (Linearity) & 0.20 & $\leq 2.0 \%$ \\
Average \%RSD (Peak area, n=3) (Intraday precision) & 0.13 & $\leq 2.0 \%$ \\
Average \%RSD (Peak area, n=3) (Interday precision) & 0.45 & $\leq 2.0 \%$ \\
Average \%Recovery (n=3) (Accuracy) & $101.02 \%$ & $100 \pm 3 \%$ \\
Average \%RSD (n=6) Peak area (Robustness) & 0.34 & $\leq 2.0 \%$ \\
Limit of detection & $0.289 \mu \mathrm{g} / \mathrm{ml}$ & $\mathrm{Lw}$ \\
Limit of quantitation & $0.965 \mu \mathrm{g} / \mathrm{ml}$ & $\mathrm{Lw}$ \\
Average tailing factor & 1.45 & $\leq 2.0$ \\
Average asymmetry factor & 1.63 & $\leq 2.0$ \\
\%RSD (Peak area, n=6) & 0.37 & $\leq 1.0 \%$ \\
\%RSD (Retention time, n=6) & 0.36 & $\leq 1.0 \%$ \\
Average number of theoretical plates & 8876.0 & $>2000$ \\
Average height equivalent to theoretical plates & $0.028 \mathrm{~mm}$ & $<0.1 \mathrm{~cm}$ \\
\hline
\end{tabular}

\section{Forced degradation studies-specificity}

$\beta$-Acetyldigoxin was subjected to various stress conditions. The results of forced degradation studies are summed up in table 3. $\beta$ Acetyldigoxin was found to be resistant to degradation under oxidative stress (percent recovery lying in $100 \pm 5 \%$ [24]). Whereas, significant degradation occurred under all other stress conditions tested. The chromatograms of stressed samples are shown in fig. 5-8.

The peak of $\beta$-acetyldigoxin was completely separated from the degradation products generated under tested stress conditions. There was no interference of any of the degradation products from the stress conditions tested in current study with the retention time of $\beta$-acetyldigoxin. Thus, the developed method for analytical determination of $\beta$-acetyldigoxin was established to be specific and stability-indicating [13].

Table 3: Results of forced degradation studies

\begin{tabular}{ll}
\hline Stress condition & Degradation (\%) \\
\hline $0.1 \mathrm{~N} \mathrm{HCl}, 40{ }^{\circ} \mathrm{C}, 30 \mathrm{~min}$. & 44.19 \\
$0.1 \mathrm{~N} \mathrm{NaOH}, 40^{\circ} \mathrm{C}, 30 \mathrm{~min}$. & 56.13 \\
$30 \% \mathrm{H}_{2} \mathrm{O}_{2}, \mathrm{RT}, 24 \mathrm{~h}$ & 3.0 \\
$\mathrm{UV}, 365 \mathrm{~nm}, 96 \mathrm{~h}$ & 36.18 \\
\hline
\end{tabular}

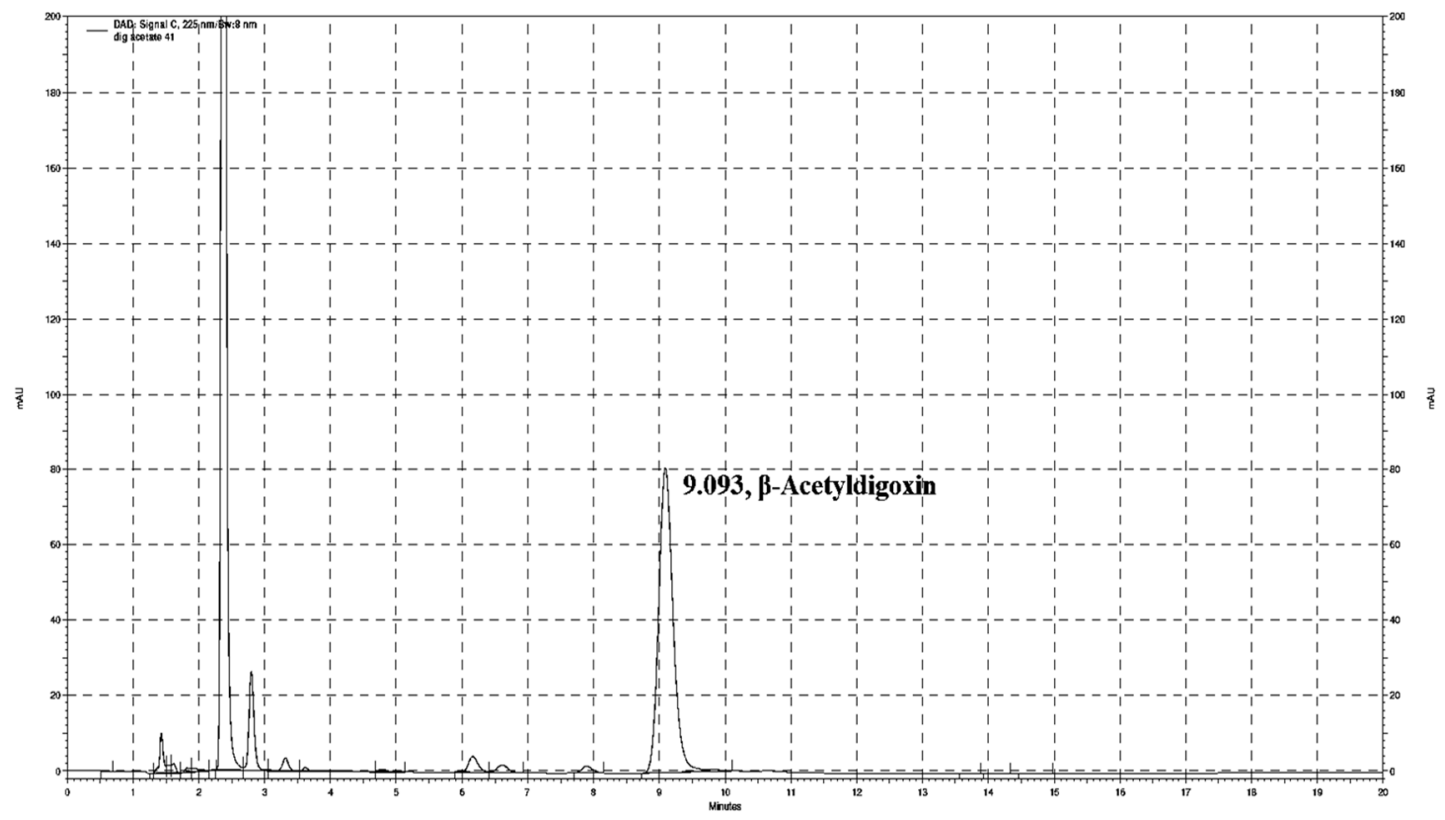

Fig. 5: Chromatogram for $\beta$-acetyldigoxin subject to acidic degradation 


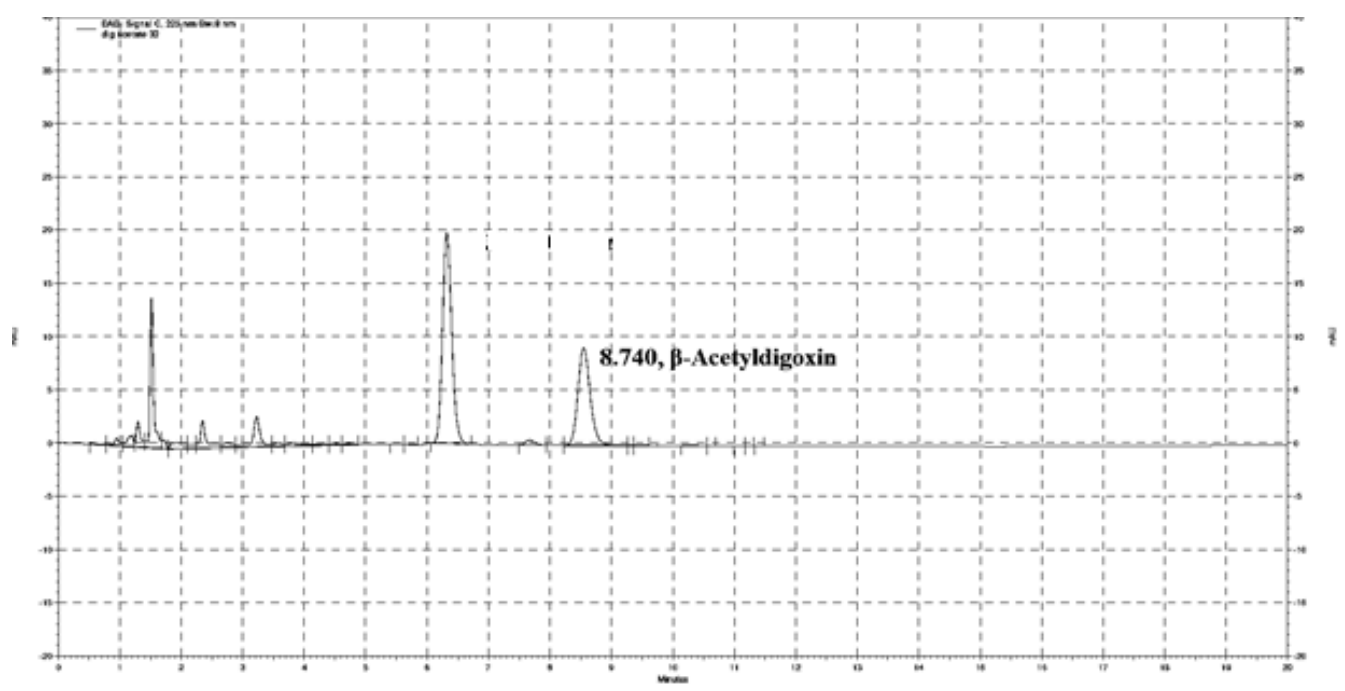

Fig. 6: Chromatogram for $\beta$-acetyldigoxin subject to alkaline degradation

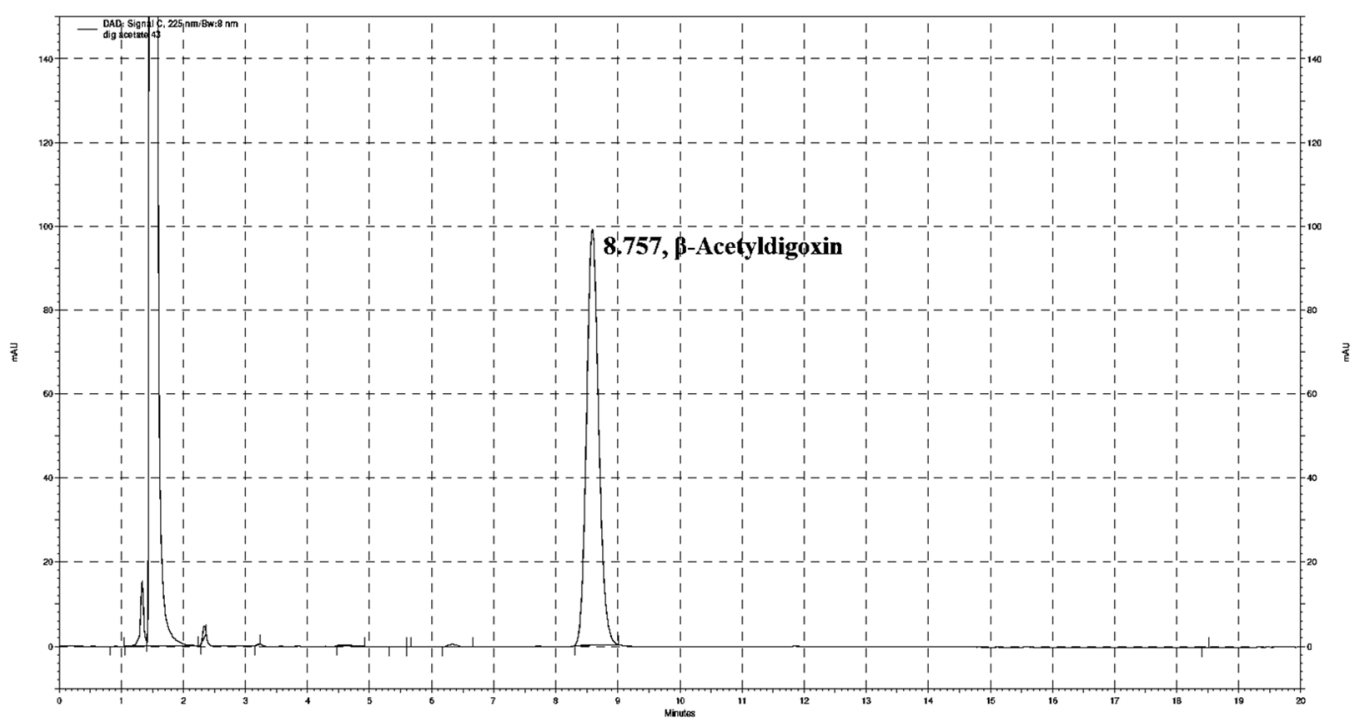

Fig. 7: Chromatogramfor $\beta$-acetyldigoxin subject to oxidative degradation

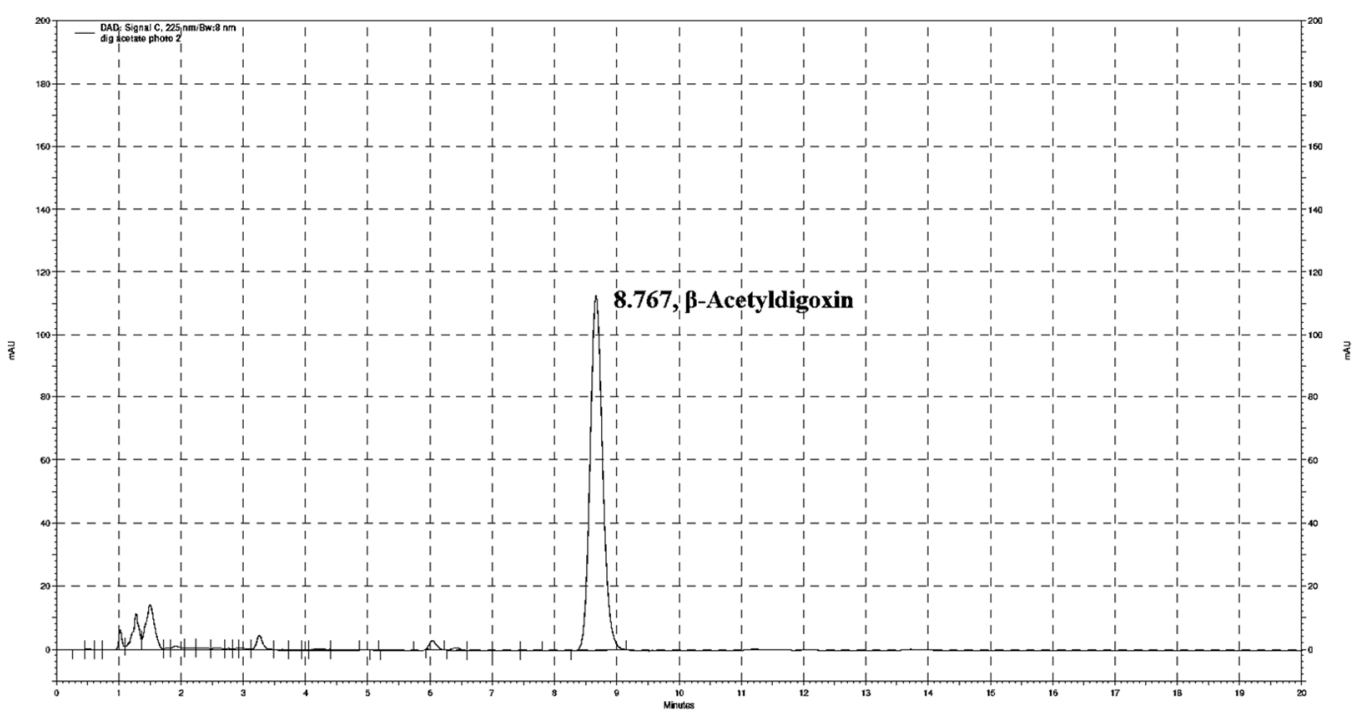

Fig. 8: Chromatogram for $\beta$-acetyldigoxin subject to photo degradation 


\section{CONCLUSION}

A novel RP-HPLC method for analytical determination of $\beta$ acetyldigoxin was developed. It was found to be simple, linear, accurate, precise, specific, robust, rapid and suitable for routine quality control and determination as API, and in pharmaceutical formulations and stability study samples. The peak of $\beta$-acetyldigoxin was distinguishable and quantifiable among the peaks of degradation products under tested stress conditions, thus the method is stability indicating. This method can be employed for determination of $\beta$ acetyldigoxin as API, and in pharmaceutical dosage forms and stability study samples. The rapidity and simplicity of this method overcomes limitations of previously reported methods, and make it suitable for routine quality control of $\beta$-acetyldigoxin.

\section{ACKNOWLEDGEMENT}

Author 1, MS, acknowledges the financial support by Department of Science and Technology, Government of India (INSPIRE FellowshipIF 130154).

\section{CONFLICT OF INTERESTS}

Declared none

\section{REFERENCES}

1. European Directorate for the Quality of Medicines. European Pharmacopoeia 7, Official monographs, $\beta$-Acetyldigoxin; 2008. p. 1315-7.

2. Julie HW. Digoxin toxicity: a review. US Pharm 2006;2:28-36.

3. Estevao LF, Fabricio PM. Digoxin's roles in heart failure patients: an overview. Insuficiencia Cardiaca 2010;5:1022-32.

4. Cheng JWM, Rybak I. Use of digoxin for heart failure and atrial fibrillation in elderly patients. Am J Geriatr Pharmacother 2010;5:419-27.

5. Flasch H, Schumpelic V, Koch G. Fate of orally administered beta-acetyldigoxin in man. Arzneimittel Forschung 1976; 27:656-9.

6. Pauli-Magnus C, Mürdter T, Godel A, Mettang T, Eichelbaum M, Klotz U, et al. P-glycoprotein-mediated transport of digitoxin, $\alpha$-methyldigoxin and $\beta$-acetyldigoxin. NaunynSchmiedeberg's Arch Pharmacol 2001;363:337-43.

7. Flasch H. Bioavailability of $\beta$-acetyldigoxin und Digoxin. Klin Wochenschr 1975;53:873-7.

8. Gruppillo P, Padovan GC, Tomaini MD, Masoni C. Therapeutic comparison between digoxin, beta-methyl-digoxin and betaacetyl-digoxin. La Clinica Terapeutica 1981;99:281.

9. Marcus FI. Pharmacokinetic interactions between digoxin and other drugs. J Am Coll Cardiol 1985;5:82-90.

10. Degner FL, Heinzel G, Narjes H, Turck D. The effect of meloxicam on the pharmacokinetics of beta-acetyl-digoxin. $\mathrm{Br} \mathrm{J}$ Clin Pharmacol 1995;40:486-8.
11. World Health Organization. IARC monographs on the evaluation of carcinogenic risks to humans. WHO 2016;108:381-419.

12. Thies PW. The modification of natural substances in the modern drug synthesis. In: New natural products and plant drugs with pharmacological, biological or therapeutical activity. Springer Berlin Heidelberg; 1977. p. 266-83.

13. Bakshi M, Singh S. Development of validated stabilityindicating assay methods-critical review. J Pharm Biomed Anal 2002;28:1011-40.

14. Rizwan SH, Sastry G. Development and validation of stability indicating RP-HPLC method for the simultaneous estimation of aliskiren hemifumarate and valsartan in bulk and pharmaceutical dosage form. Asian J Pharm Clin Res 2015;8:223-7.

15. Plum J, Daldrup T. Detection of digoxin, digitoxin, their cardioactive metabolites and derivatives by high-performance liquid chromatography and high-performance liquid chromatography-radioimmunoassay. J Chromatogr B 1986;377:221-31.

16. Desta B, Kwong E, McErlane KM. Separation of digoxin, digitoxin and their potential metabolites, impurities or degradation products by high-performance liquid chromatography. J Chromatogr A 1982;240:137-43.

17. Kazakevich YV, LoBrutto R. editors. HPLC for Pharmaceutical Scientists. Wiley Publishers; 2007. p. 788.

18. International Conference on Harmonization (ICH), Q2(R1): Validation of analytical procedures: text and methodology; 2005.

19. Chapter G. Validation of compendial methods, United States Pharmacopeia. The United States Pharmacopoeia Convention. Rockville, MD; 2003.

20. FDA, Guidance R. Validation of chromatographic methods Center for Drug Evaluation and Research (CDER), Food and Drug Administration; 1994. p. 2.

21. Jain HK, Deore DD. Bioanalytical method development and validation for estimation of clopidogrel bisulfate in human plasma by RP-HPLC. Int J Appl Pharm 2016;8:18-21.

22. Ahuja S, Dong M. editors. Handbook of Pharmaceutical Analysis by HPLC. $1^{\text {st }}$ ed. USA: Elsevier-Academic Press; 2005.

23. FDA, ORA Validation and Verification Guidance for Human Drug Analytical Methods. Food and Drug Administration; 2003. p. 1.

24. FDA, Department of Health and Human Services, 510 (k) Summary Elecsys Progesterone III Calset, Food and Drug Administration; 2015. p. 45.

\section{How to cite this article}

- Megha Sharma, Neeraj Mahindroo. Development and validation of stability indicating RP-HPLC method for determination of $\beta$ acetyldigoxin. Int J Appl Pharm 2017;9(1):54-59. 